\title{
Woodfuel production and trade in Choma District, Zambia
}

Kaala B. Moombe, Bravedo M. Mwaanga, Davison Gumbo, Markus Ihalainen and Jolien Schure

\section{Key messages}

- Strong dependence on woodfuel for domestic energy consumption in Zambia increasingly puts pressure on production areas. However, miombo woodland species hold good potential for recovery through assisted natural regeneration.

- Most woodfuel is sourced from customary land under the care of traditional authorities, with small amounts coming from state land. However, strategies for woodfuel management are lacking from both authorities.

- Efficient and sustainable woodfuel management is hampered by weak concerted efforts, and limited communication and coordination among relevant stakeholders. Interactions are particularly limited at feedstock production and management levels.

- Rules and laws aimed at regulating the use of forest resources exist within the sector, yet enforcement is generally weak and fragmented due to capacity constraints, overlapping or contradicting mandates and limited collaboration.

- Actor networks along the woodfuel value chain, representing mandates regarding enforcement, extension, transportation and production, are concentrated around the Forestry Department, with links to chiefdoms, charcoal association groups, transporters and end users.

- Existing producer networks can play an important role in facilitating legal and sustainable charcoal production and trade. Clarifying group and association mandates, benefits and responsibilities, and enhancing communication are key to success.

\section{Introduction}

The Center for International Forestry Research (CIFOR), Forest and Farm Facility (FFF) and other partners, undertake activities in Zambia to generate evidence, knowledge and options for more sustainable woodfuel value chains under the project entitled Governing Multifunctional Landscapes (GML) in sub-Saharan Africa, launched in 2018. This brief summarizes the key learnings from the biophysical and institutional assessments undertaken in Choma District. This overview of the state of the resource base and the institutional mechanisms in place, provides insights on options for the sustainable management of woodfuel value chains.

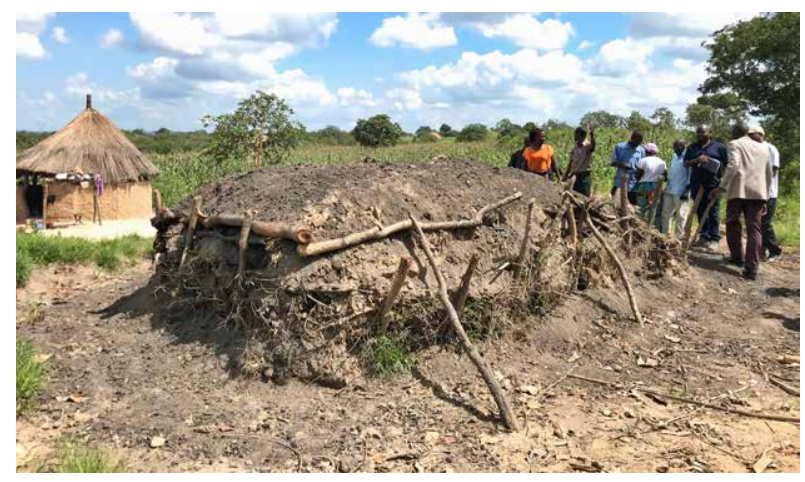

Traditional charcoal kiln, Choma, Zambia.

Photo: Jolien Schure 


\section{Woodfuel in Zambia}

Woodfuel issues in Zambia, including such areas as the woodfuel-producing Choma District (CIFOR 2020), are becoming increasingly urgent given that woodfuel caters for around $90 \%$ of domestic energy needs in both urban and rural areas and demand is rising (Gumbo et al. 2013; ZDA 2014). Further, woodfuel production and trade are blamed for woodland loss in Zambia, and charcoal production alone has been shown to contribute to close to $25 \%$ of the 300,000 ha/year of forests lost (Kalinda et al. 2008; Vinya et al. 2013). With much of the charcoal production taking place in forestry reserves and open lands, it is critical to understand how individuals, communities and institutions involved operate and interact to inform policy actions around enhancing the inclusiveness and sustainability of woodfuel value chains.

\section{Choma's miombo woodlands}

Choma District hosts a mosaic landscape of alternating crop fields, fallow lands, grasslands, streams, dams and secondary forests (Figures 1 and 2), mainly on miombo woodlands. Some pockets of primary forest remain on private lands or in the more remote southern parts of the district. In most areas, human activities, including tree cutting for charcoal or timber, agriculture and pastoralism, have affected forest and tree resources in the miombo woodlands. A forest inventory

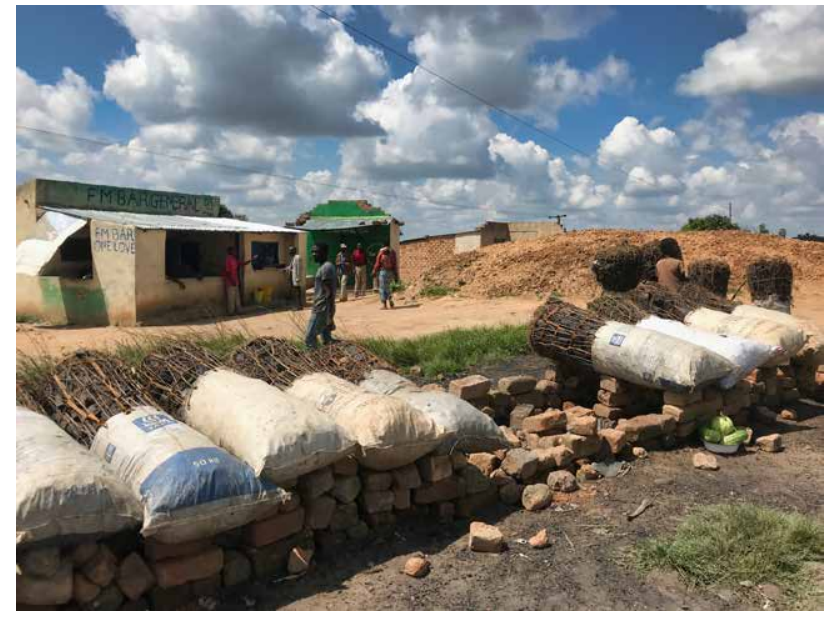

Charcoal sales at roadside, Choma, Zambia.

Photo: Jolien Schure

conducted by CIFOR in 2019, confirmed strong degradation of miombo woodland species, leaving Choma District with limited availability of sizable trees suitable for charcoal production (Figure 3). However, the regeneration capacity of 42 different tree species has been confirmed (see Figure 4 for the top-5 most frequent regenerating species), showing good potential for the assisted natural regeneration of these woodland species under improved management strategies, besides protecting them from threats of overharvesting, fires and grazing (CIFOR 2019).
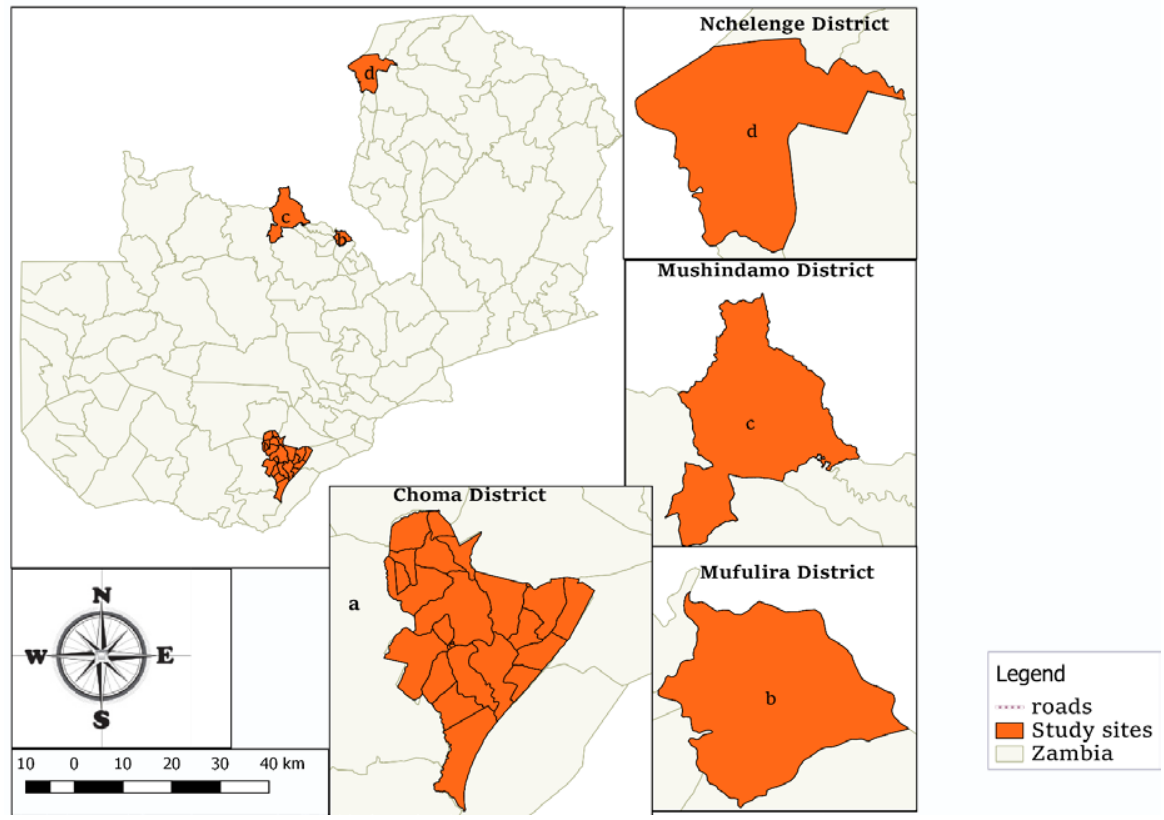

Figure 1. Choma District (a, including wards on Zambia map), Mufulira (b), Mushindamo (c) and Nchelenge (d), are the other sites in Zambia where the Governing Multifunctional Landscape (GML) program is undertaking activities on the improved sustainability of woodfuel value chains. 


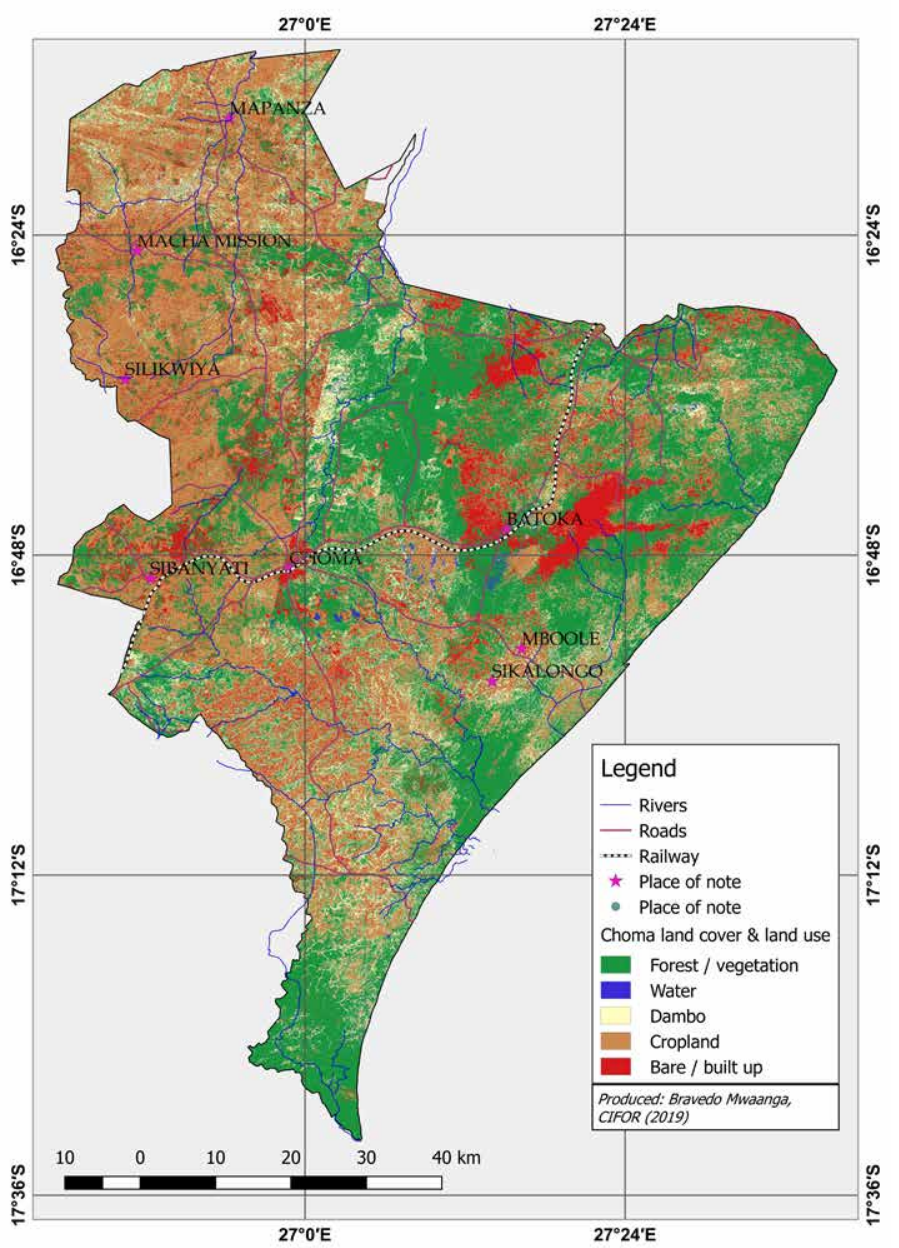

Figure 2. Choma land cover classification for Choma district.
Woodfuel value chains in Choma District are currently characterized by a lack of sustainable practices, including unplanned cutting and use of low-efficiency earth kilns. Citing concerns over deforestation, the Chief of Cooma Chiefdom had imposed a ban on charcoal production. Yet our findings suggest that charcoal production continues in the area, with even fruit trees being cut for charcoal. Few producers obtain licenses from the Forestry Department due to relatively high costs, cumbersome processes and the short validity period of permits. Producers also report malpractices along the value chain, such as confiscation of charcoal for personal gain by controlling agents. In general, the pricing of charcoal, especially in the marketplaces between the retailers and the producers, does not include the full costs of tree resources and labor. The latter suggests that market price of charcoal may only be higher than currently is.

CIFOR conducted an institutional assessment in Choma in 2019 to assess how institutions participating in and governing woodfuel production and trade in Choma District shape outcomes and affect sustainable management and production methods.

\section{The players}

Many state and non-state actors are involved in woodfuel production and trade in the Choma District, influencing the value chain through formal

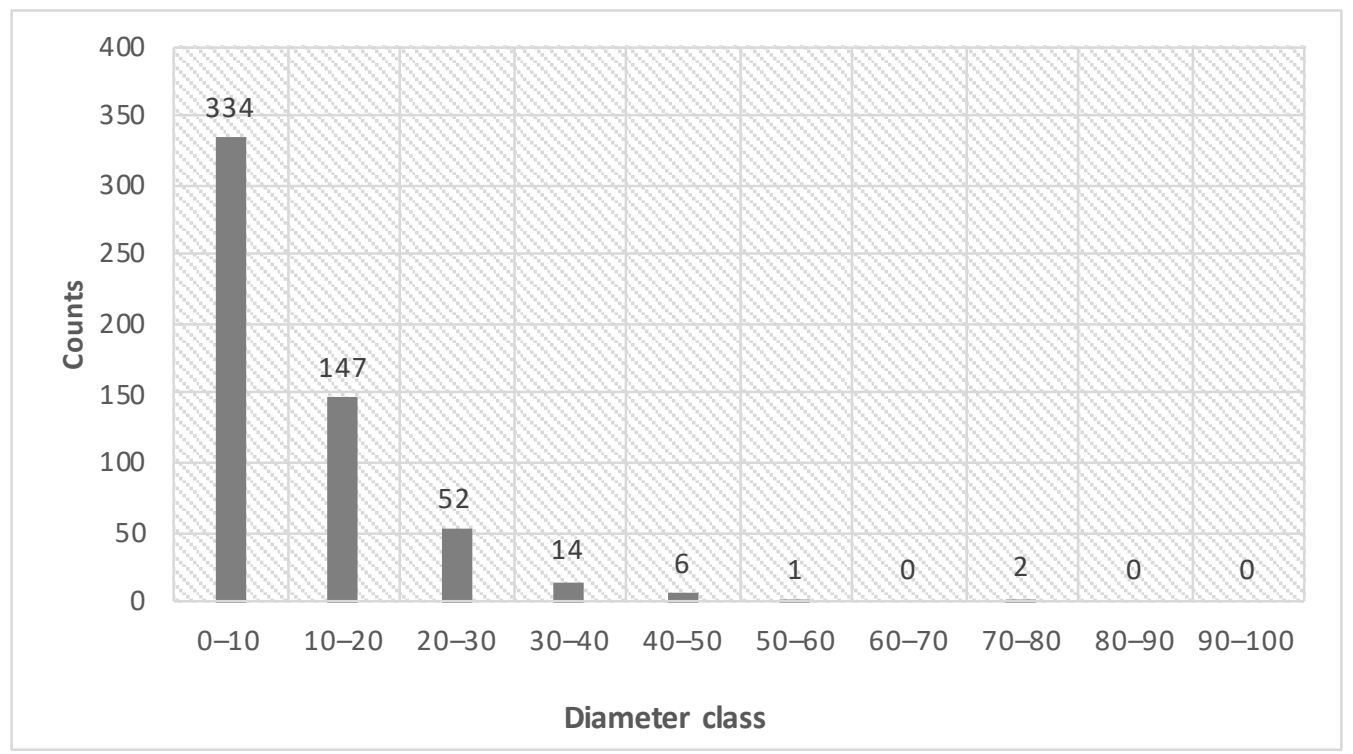

Figure 3. The size class distribution for diameter at breast height (dbh), i.e. at $1.3 \mathrm{~m}$, for all recorded tree species (dbh $\geq 5 \mathrm{~cm}$ ) in Choma District. 


\section{The rules of the game}

Both written and unwritten rules apply to the management and control of woodfuel harvesting and trade. At community level, there are agreements on the headman's role in regard to how trees are taken care of and in monitoring the use of trees by community members. Other rules at the level of the chiefdom include prohibition of charcoal production, sometimes specific to groups such as women nursing young children; prohibition of charcoal movement that has not been licensed by the Forestry Department; and the application of rules for standardized pricing by the Choma Charcoal Association. There are penalties for the violation of the rules, including being handed over to state police, fines at chiefdom level and membership suspension from Charcoal Producer Groups.

At government level, various legal frameworks apply to the management of woodfuel, from its production, through to transportation and sales (Table 1). Penalties for violations of these laws may comprise fines or imprisonment, or both.

\section{Reality of woodfuel production and trade under existing institutional framework}

In reality, production and trade activities take place within a context of legal plurality, often under informal arrangements and without observation of the official rules. At present, there are no overarching laws or policies regarding the Choma, tobacco growers and the Zambia Prisons Service are important local users of firewood. involved include the Forestry Department; the Chiefdom Cooma, Macha and Mapanza; Judiciary Department; Choma District Council (CDC); Choma District (Administration); groups (CPGs). Charcoal production is for consumer households, in the urban markets of Choma and even as far as the Zambia's capital city, Lusaka. Households in

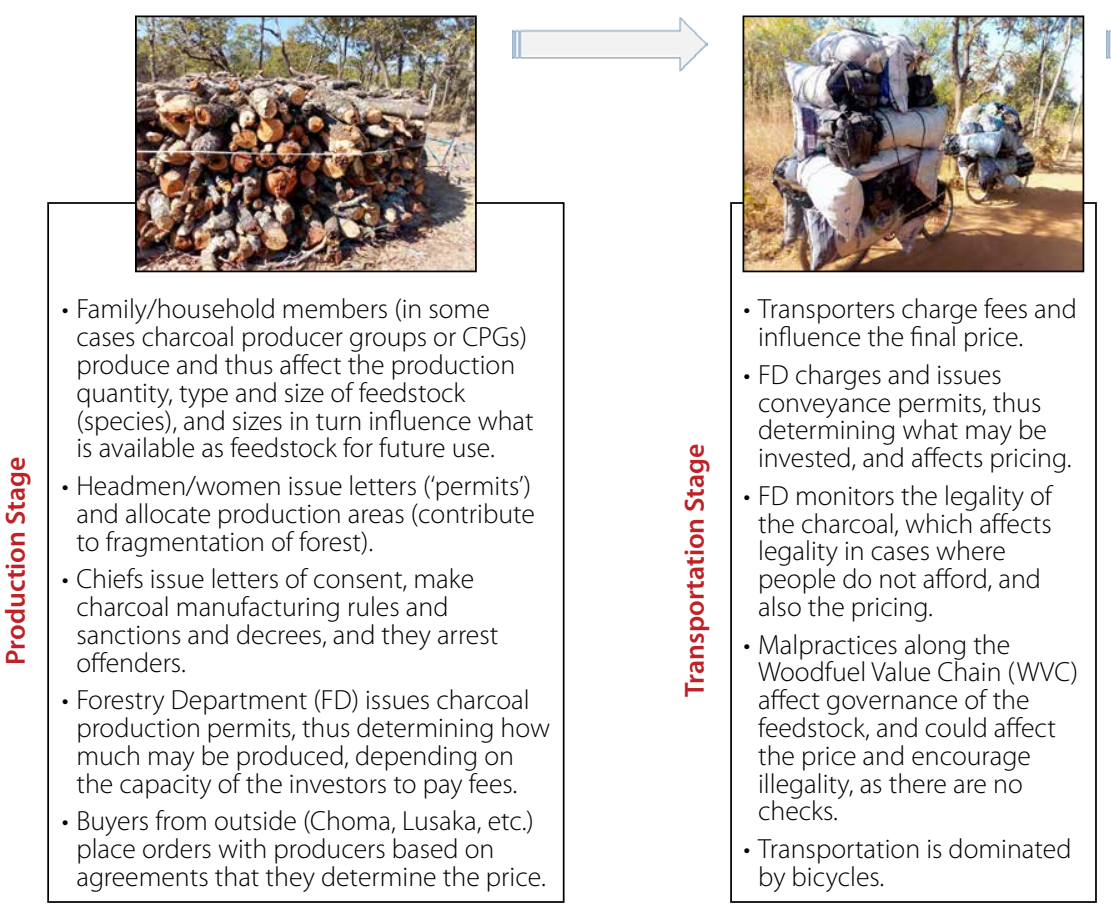

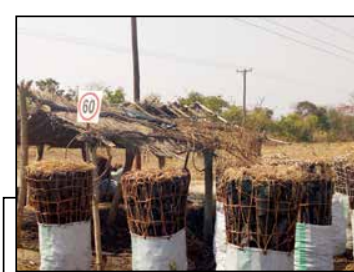

- Council provides marketplaces and so facilitates trade, and thus, supply.

- Council collects a levy that affects pricing and also legality when people avoid selling fom markets.

- Choma Charcoal Association (CCA) retailers charge membership fees, thus affecting pricing.

- End users facilitate the demand-supply nexus, and affect the profitability of the forest-based enterprise.

Figure 5. The woodfuel value chain, the type of players and their roles. 
Table 1. Laws and the relevant restrictions on the woodfuel value chain.

\begin{tabular}{ll}
\hline Law & Restriction or requirement \\
\hline Forests Act, 4/2015 & - No cutting of a tree without a permit \\
& - No production of charcoal without a license \\
& - No movement of charcoal without a conveyance permit \\
& - A license or permit is nontransferable \\
\hline EMA 2011 (sec. 120) & - There is a prohibition on all persons from trading in, unlawfully possessing and \\
& disturbing the habitat of any component of biological resources \\
\hline $\begin{array}{l}\text { Markets and Bus Stations Act No. 2007 } \\
\text { (MBA 7/2007) }\end{array}$ & - Market payment of fees, stallage or levy \\
\hline $\begin{array}{l}\text { Trades Licensing Act No. 13 of 1994 } \\
\text { (TLA 13/1994) }\end{array}$ & - Manufacturing licenses for goods, which may include charcoal \\
\hline $\begin{array}{l}\text { Statutory Instrument No. } 94 \text { of 2015 } \\
\text { (SI 94/2015 }\end{array}$ & - Prohibition of export of charcoal \\
\hline $\begin{array}{l}\text { Trades Licensing Act No. 13 of 1994, } \\
\text { TLA 13/1994 }\end{array}$ & - Licenses required: peddler's, wholesale trading, retail trading, agent's, hawker's \\
\hline
\end{tabular}

woodfuel value chain. Control systems at both community and state levels are weak or nonexistent, and there are no clear links to resource management plans around harvesting and the issuance of related documents.

Under traditional governance arrangements, villagers generally obtain a letter from a headman/woman. The headperson subsequently identifies an area (and may not even visit it at times) within the customary lands and issues a letter allowing the applicant to manufacture charcoal. The letter is then taken to the chief for endorsement, and payments are due to both the head person and the chief. According to producers, this process is cumbersome because it is timeconsuming and sometimes open to abuse and self-enrichment.

In some areas and cases, the headmen/women do inspect the production area, ascertain the land status (farm or communal land) and check with the interested party (villager) on the availability of trees sources, before issuing authorization letters to producers. However, there are no comprehensive control mechanisms on subsequent production practices and the actual quantities of wood being harvested. Letters of no objection and recommendations to the Forestry Department by traditional authorities have been perceived as 'official' permits by some of the 'would-be' charcoal producers.

The government, through the Forestry Department, also issues permits for production, conveyance and trade concerning customary areas. There is no regular pre- or post-assessment of the resource base and charcoal manufacturing sites. Monitoring activities by the Forestry Department are conducted through roadblocks and patrols, mainly along main transport routes and at markets. As the transport of charcoal from production sites to local markets is often organized by charcoal traders, the responsibility of obtaining and producing required licenses lies mostly with traders. One of the interviewed transporters noted that village headmen/women occasionally verify that transporters possess formal production and conveyance licenses before allowing transportation of the charcoal to marketplaces. At the same time, some producers also noted that without proper licenses, they run the risk of being fined or having their charcoal confiscated. Producers without licenses/permits risk their charcoal being confiscated by the state. The figure 6 shows actor network and relationships ranging from government (Forestry Department- FD, Council, Zambia Police, and Zambia Correctional ServiceZCS), Traditional (Chiefs, subjects i.e. transporters, small scale individual tobacco farmers) and Private (Private tobacco farmers, Tobacco Board of Zambia-ZBD, Choma Charcoal Association- CCA, and Charcoal Producer Associations- (PAs). Private tobacco farmers include commercial producers while Individual tobacco farmers include small scale producers.

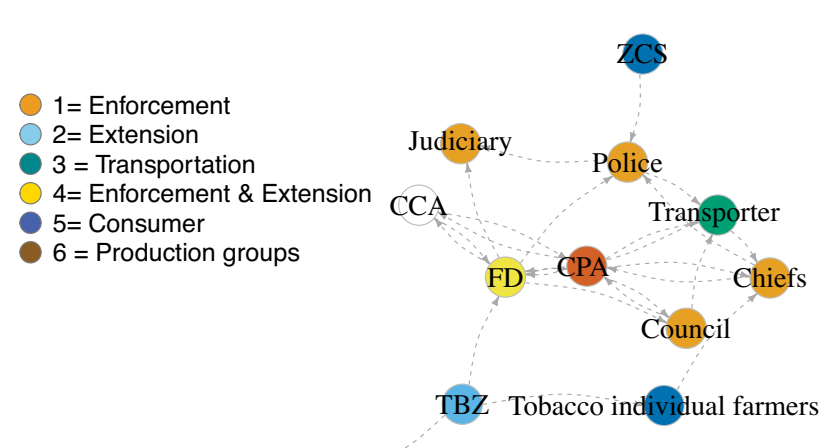

Tobacco private farmers

Figure 6. Actor network and relationships linkages. 
The Forestry Department (FD) in collaboration with the Choma District Council are key actors within the actor network (Figure 6). The FD's different mandates of law enforcement, tax collection and extension and advisory services cause ambiguity about its roles and responsibilities toward other stakeholders, including the producers and local authorities. At present, the FD lacks sufficient capacity to monitor charcoal production activities and sustainable wood sourcing. The link between authorization for wood extraction with sustainable management plans or monitoring of available resources is weak.

The Choma Charcoal Association (CCA) as well as the charcoal producer groups (CPGS) organized under the CCA are relatively young organizations ${ }^{1}$, initiated by the Forestry Department and supported by the FFF, with the mandate to represent the interests of members concerning the charcoal sector. This includes advocating for a conducive operational and regulatory environment for members and capacity enhancement regarding their organizational capacities, and improved resource management, charcoal production and trade practices. Thus far, the CPGs have been involved in tree planting and management activities, awareness raising on forest laws and regulations, tests on improved technologies for charcoal production and planning on potential charcoal bulking centers.

The first CPGs were mobilized in 2015 and there are currently 33 active CPGs in Choma, most of them (about two-thirds) operating in the Cooma Chiefdom. At the aggregate level, the membership appears to be gender-balanced with adult men (39.4\%), adult women (49.2\%) and youths (11.4\%). However, membership tends to be heavily femaledominated in retailer groups, while production-oriented groups tend to have more men than women.

Members largely joined a CPG because they expected that it would facilitate their access to licenses and believed it to be a legal requirement, as is currently being proposed in the draft charcoal regulations. Some members thought that membership would bring them access to improved technologies and financial services, while a few - mainly women - hoped to be taught how to produce charcoal.

Reported benefits of membership of CPGs are networking and access to knowledge and training, particularly on more sustainable extraction practices. Relationships between members and the Forestry Department have improved and they have been able to take part in tree planting. However, given that many of the expected benefits were based on

1 The first CPGs were mobilized between 2015 and 2017, while the CCA was formally established in August 2017.

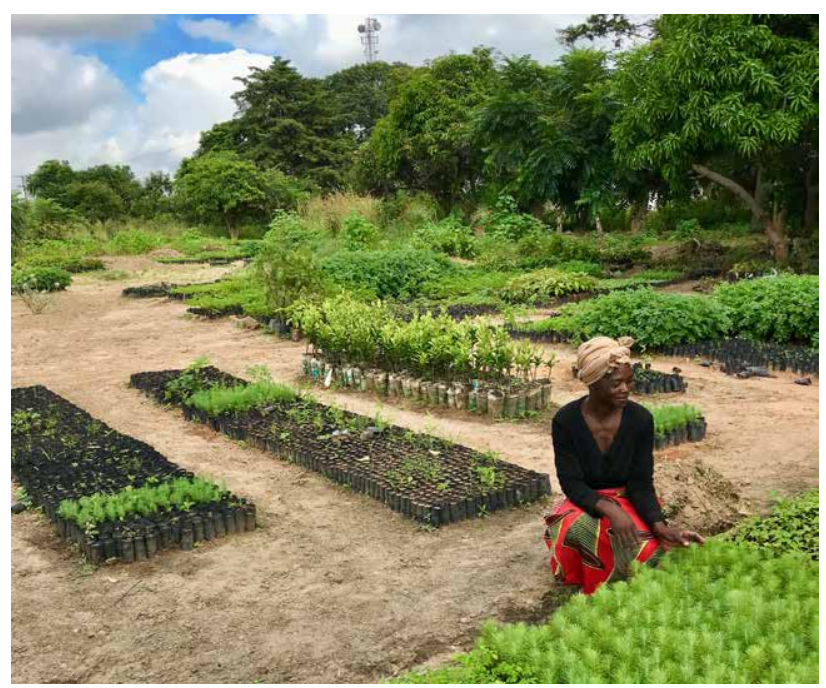

Member of Charcoal Producers Group at tree nursery, Choma, Zambia.

Photo: Jolien Schure

misinformation and/or misunderstandings, a number of respondents perceived benefits to be limited. In most cases, CPG members opted to remain in the group, hopeful that benefits would materialize in the future, while members in a few groups noted that some had started dropping out due to unmet expectations and membership costs ${ }^{2}$.

Our study of the network identified poor coordination between the CPGs and the CCA. Most CPG members were not aware of the CCA or its mandate, while some complained that CCA meetings were only attended by the CPG leaders, who often failed to share information with the rest of the members. Other challenges included poor coordination among state, traditional institutions and the CCA; limited access to licenses, funds, seedlings and other resources; a ban on charcoal production by traditional authorities; malpractices; limited capacity for collective bargaining; and unmet expectations for members. In some cases, traditional leaders have not been aware of the existence and operations of the CPGs in their chiefdoms, as the CPGs had been set up without their involvement.

\section{Ways forward for sustainable woodfuel in Choma District}

Degradation of miombo woodlands in Choma not only causes severe environmental impacts, but also obstructs long-term use of tree species for income generation, and energy and construction, including charcoal supply. Miombo wood species are resilient and show good regeneration capacity, but this requires targeted management of

2 Annual membership fees range from ZMW10 (USD 0.8) to ZMW 50 (USD 3.9). 
woodfuel sourcing. At present, the availability of wood for charcoal production and the quality of woodlands are not being sufficiently well addressed by traditional authorities and the Forestry Department; filling this gap would help inform their tasks of overseeing harvesting, production and trade activities. While charcoal production continues to increase in Choma District, management systems and the use of more efficient harvesting and production methods lag behind.

The institutional assessment shows strengths and the willingness of actors involved along the woodfuel value chains to address sustainable management practices. To tap into these strengths, the following need to be addressed.

\section{Strengthen linkages and communication between} institutions involved along the woodfuel value chain, to clarify roles and responsibilities, with the common objective of guaranteeing long-lasting woodfuel supply from sustainable sourcing and efficient practices. Better collaboration between traditional leadership, the state (Forestry Department) and producer groups can greatly enhance monitoring and enforcement of sustainable sourcing and production.

\section{Choma Charcoal Association and Charcoal Producer} Groups have important roles in representing their members' interests, including giving advice on appropriate formalization of their charcoal operations and charcoal pricing, and capacitating them in environmentally sound and economically smart practices. The mandate of these groups, together with the rights and responsibilities of members should be clearly communicated for informed decisions on membership and participation. Links between the CPGs and the CCA must be strengthened and accountability measures introduced to ensure CPG members receive information from the CCA and are able to influence its operations. Producer groups need to be capacitated on collective bargaining and organizational aspects, and on how to do environmental assessment and resource management of their production sites, including tree planting and access to seedlings. Implementation of the PGS for charcoal would be a good step forwards to reach this.

There is a need for additional extension and advisory services on improved woodfuel management with targeted messages towards producers, including providing information about:

- the Choma Charcoal Association, its purpose, functions, benefits, and in particular the ways in which it represents and engages with CPGs

- clear understanding of the incentives to implement sustainable charcoal, such as the roll-out of the Participatory Guarantee System for charcoal (see Box 1)

\section{Box 1. Certifying sustainable charcoal: The Participatory Guarantee System for Charcoal in Choma}

\section{Sophie Grouwels and Vincent Ziba}

The Participatory Guarantee System of certification (PGS) was originally developed for smallholder organic agriculture producers and is recognised by the International Federation of Organic Agriculture Movements (IFOAM - Organics International). PGS provides a locally focused quality assurance system and is also referred to as 'participatory certification'. PGS certifies producers based on active participation by stakeholders and is built on a foundation of trust, social networks and knowledge exchange. PGS represents an alternative to more expensive thirdparty certification schemes to ensure transparency and integrity among producers and consumers. Through PGS, the consumers and producers of a certain product agree on conditions for production and the way these will be verified by allowing participation of all stakeholders in:

- the choice and definition of the standards

- the development and implementation of verification procedures

- the review and decision process to recognize producers

The FFF, in collaboration with the Forestry Department, has established a pilot project for developing a PGS framework for sustainable charcoal production in Zambia.

A participatory sustainable charcoal production guideline was developed, drawing from government timber harvesting guidelines, principles for sustainable forest management, Government Forest research notes 29 and 30, and community indigenous knowledge. Village-level PGS action groups were established and trained to support implementation of the practices defined in the guidelines. A total of 15 people were trained as PGS mobilizers from all the chiefdoms of Choma and a total of 215 community members were sensitized.

The PGS for charcoal will provide an incentive for approving charcoal production under community forest management and a tool for stakeholders' participation in monitoring sustainable charcoal production. With the FD's commitment to preferential market places for charcoal under the PGS, this can offer a first-of-a-kind incentivization mechanism for sustainable charcoal practices in Zambia. 
- $\quad$ traditional rules on natural resources management

- legal provisions and processes for woodfuel production and trade

- $\quad$ woodland or tree management linked to woodfuel supply

- $\quad$ access to quality seedlings

Governance of woodfuel value chains needs to be improved, through stakeholder dialogue that informs the development of a woodfuel production and trade governance and monitoring framework with clear roles, responsibilities and benefits. This should include alignment of access controls such as permit issuance by both the state (e.g. according to the Forests Act, 4/2015) and non-state actors (e.g. letters of consent from either chiefs or headmen/women). These governance mechanisms and the improved woodfuel management can be integrated in a current review of chiefdom development strategic plans and the charcoal regulation's subsidiary law under drafting.

\section{References}

[CIFOR] Center for International Forestry Research. 2020. Choma institutional assessment. Lusaka: CIFOR.

[CIFOR] Center for International Forestry Research. 2019.

A biophysical assessment of production systems in
Choma district. Choma Forest Inventory Field Report (preliminary version). Lusaka: CIFOR.

Gumbo DJ, Moombe KB, Kandulu MM, Kabwe G, Ojanen M, Ndhlovu E and Sunderland TC. 2013. Dynamics of the charcoal and indigenous timber trade in Zambia: A scoping study in Eastern, Northern, and Northwestern Provinces. Bogor: CIFOR.

Kalinda T, Bwalya S, Mulolwa A and Haantuba H. 2008. Use of Integrated Land Use Assessment (ILUA) data for environmental and agricultural policy review and analysis in Zambia. Report prepared for the Forest Management and Planning Unit of the Forestry Department, FAO and the Zambian Forestry Department.

Ministry of Tourism, Environment and Natural Resources, Zambia. Lusaka: Forestry Department/Food and Agriculture Organization of the United Nations. http://www.fao.org/ forestry/16955-0c90798cee1e59a8542ede210a9834227.pdf

Moombe,K B. 2018. Technical Report on Institutional Woodfuel Framework in Zambia. The Forests Act No. 4 of 2015. Woodfuel Production and Trade Legal and Institutional Framework.

Vinya R, Syampungani S, Kasumu EC, Kasubika R and Moonde, C. 2013. Drivers of deforestation and potential for carbon trading in miombo woodlands. In Manzares L, ed. Woodlands: Structure, Species Diversity, and Sustainable Management. USA: NOVA Publishers. 99-118.

[ZDA] Zambia Development Agency. 2014. Zambia energy sector profile. Lusaka: Zambia Development Agency. Accessed January 2016. https://ab-network.jp/wp-content/ uploads/2014/07/Energy-Sector-Profile.pdf

This publication is part of the project Governing Multifunctional Landscapes (GML) in sub-Saharan Africa, an initiative funded by the European Union and led by CIFOR. The Forest and Farm Facility (FFF) is an implementation partner in Zambia.

\begin{tabular}{|l|l|l} 
& This research was carried out by CIFOR-ICRAF as part of the CGIAR Research Program on Forests, \\
Trees and Agroforestry (FTA). FTA is the world's largest research for development program to \\
enhance the role of forests, trees and agroforestry in sustainable development and food security \\
and to address climate change. CIFOR leads FTA in partnership with Bioversity International, \\
CATIE, CIRAD, INBAR, ICRAF and TBI. \\
FTA's work is supported by the CGIAR Trust Fund: cgiar.org/funders/
\end{tabular}
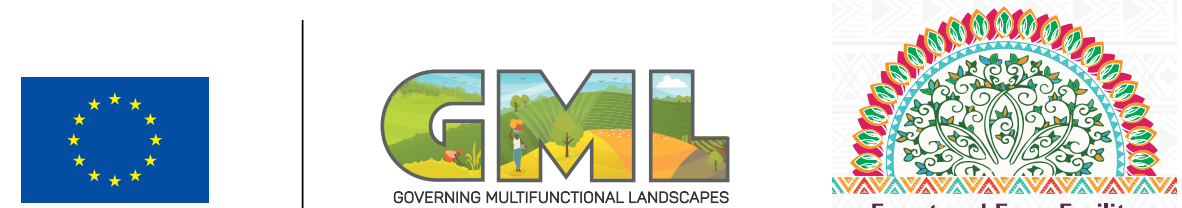

Forest and Farm Facility NVAVAVAVAVAVAVAVAVAVAV/

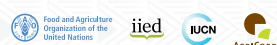

